\title{
Analisa Kapasitas Optimal Lapangan Penumpukan di Pangkalan Lontangnge Pelabuhan Parepare
}

\author{
Anugrah Amaliah ${ }^{1 *}$, Syarifuddin Dewa ${ }^{1}$, Misliah Idrus ${ }^{1}$ \\ ${ }^{1}$ Departemen Teknik Perkapalan, Fakultas Teknik, Universitas Hasanuddin \\ Jl. Poros Malino Km. 6, Bontomarannu, Kabupaten Gowa, Sulawesi Selatan, 92171 \\ *Email: anugrahamaliah.inaport4@gmail.com
}

DOI: 10.25042/jpe.052018.13

\begin{abstract}
Abstrak
Perencanaan pelabuhan yang tidak tepat dapat mengakibatkan pelayanan pelabuhan yang kurang efisien. Optimasi digunakan untuk menemukan sebuah kondisi yang diperlukan untuk mencapai hasil terbaik dari situasi yang ada. Hal ini dicapai dengan menyeimbangkan antara biaya pelayanan yang ada dengan biaya tunggu yang diakibatkan oleh pelayanan yang ada. Biaya pelayanan tergabung dalam pengoperasian fasilitas sedang biaya tunggu menyatakan biaya menunggu bagi pelanggan. Menambah ataupun meningkatkan pelayanan berarti dapat mengurangi waktu tunggu pelanggan. Penelitian ini bertujuan untuk menganalisis kapasitas optimal Lapangan Penumpukan Petikemas Lontangnge Pelabuhan Parepare untuk jangka pendek, jangka menengah dan jangka panjang, serta menentukan dimensi ukuran dari Lapangan Penumpukan Petikemas Lontangnge Pelabuhan Parepare. Analisa dilakukan dengan menggunakan teori antrian, dimana teori ini membantu dalam menghitung biaya-biaya akibat pelayanan yang menunggu. Perhitungan ini dilakukan dengan menganalisa data muatan bongkar-muat (B/M) petikemas dan data barang pada petikemas untuk memperoleh biaya yang ada. Selain itu, dilakukan pula perhitungan daya dukung tanah untuk menentukan tinggi tumpukan petikemas dan kapasitas lapangan. Pada hasil penelitian ini, diperoleh untuk Jangka Pendek biaya optimum untuk Lapangan Penumpukan Petikemas Lontangnge Pelabuhan Parepare adalah Rp. 27,479,774,886.03 dengan luas dimensi lapangan adalah $4700 \mathrm{~m}^{2}$. Sedangkan untuk Jangka Menengah dan Jangka Panjang adalah Rp. 36,690,983,344.01 dengan luas dimensi lapangan adalah $25000 \mathrm{~m}^{2}$.
\end{abstract}

\begin{abstract}
Optimal Capacity Analysis of Stacking Fields at Lontangnge Base, Parepare Port. Improper port planning results in less efficient port services. Optimization is used to find the one condition to find the best outcome of the situation. This is achieved by balancing the cost of existing services with the waiting costs caused by existing services. Service charges are incorporated in the operation of the facility while the waiting costs state the waiting costs for customers. Adding or improving services means reducing customer waiting times. The aim of this research is to analyze the optimal capacity of Lontangnge Container Yard Port of Parepare, medium and long term, and to determine the dimension of container yard's size. The analysis is done by using queuing theory, where the costs of waiting service can be calculated. This calculation is done by analyzing data of loading-discharging payload and goods data on container to obtain cost. In addition, the calculation of soil bearing capacity is also determined the height of container pile and Container Yard (CY) capacity. In the results of this study, obtained for the short-term optimum cost for the Lontangnge Parcel Container Parepare Field is Rp. $27,479,774,886.03$ with the width of field dimension is $4700 \mathrm{~m}^{2}$. While for the Medium Term and Long Term is Rp. $36,690,983,344,01$ with the field dimension is $25000 \mathrm{~m}^{2}$.
\end{abstract}

Kata Kunci: Kapasitas lapangan, muatan B/M, optimasi

\section{Pendahuluan}

Dalam rangka implementasi Undang-Undang Nomor 17 Tahun 2008 tentang Pelayaran dan Peraturan Pemerintah Nomor 61 Tahun 2009 tentang Kepelabuhanan, setiap pelabuhan wajib memiliki Rencana Induk Pelabuhan, serta untuk penyelenggaraan pelabuhan yang efektif dan efisien perlu disusun Daerah Lingkungan Kerja
Pelabuhan (DLKr) dan Daerah Lingkungan Kepentingan Pelabuhan (DLKp). Untuk menyongsong realisasi RIP yang telah disusun oleh setiap pelabuhan, tentunya akan ada perubahan-perubahan yang terjadi berdasarkan perkembangan pelabuhan terkait [1].

Untuk melaksanakan kegiatan kontainerisasi tersebut, PT Pelabuhan Indonesia IV (Persero) 
Cabang Parepare ditunjang oleh fasilitas pelabuhan yang mendukung yaitu berupa dermaga, terminal penumpang, lapangan penumpukan dan fasilitas pendukung lainya. Dalam rangka menguatkan daya dukung fasilitas, maka PT Pelabuhan Indonesia IV (Persero) Cabang Parepare kini telah mulai membangun sistem operasional petikemas.

Tingkat pemanfaatan fasilitas pelabuhan merupakan salah satu jenis kinerja pelabuhan yang berfungsi sebagai alat analisis penting bagi manajemen didalam mengelola pelabuhan, menentukan perencanaan dan pengembangan serta menetapkan kebijakan-kebijakan [2].

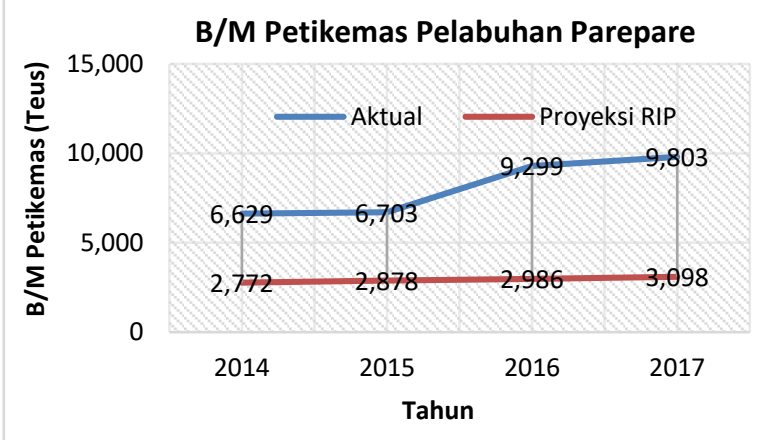

\section{Gambar 1. Perbandingan nilai arus $B / M$ petikemas} secara aktual dengan nilai hasil proyeksi RIP.

Dalam perencanaan pengembangan fasilitas kepelabuhanan khususnya fasilitas pelayanan petikemas, tentunya diharapkan untuk sejalan dengan RIP yang telah ditetapkan, untuk itu RIP telah menyajikan proyeksi Arus B/M Petikemas dan memprediksi luas lapangan penumpukan yang dibutuhkan.

Gambar 1 menunjukkan proyeksi RIP yang meningkat dari 2.772 teus menjadi 3.098 teus atau dapat dikatakan proyeksi tingkat pertumbuhan rata-rata dari tahun 2014 hingga tahun 2017 adalah $3.64 \%$. Sedangkan realisasi aktual menunjukkan peningkatan dari 6.629 teus menjadi 9.803 teus atau dapat dikatakan proyeksi tingkat pertumbuhan rata-rata dari tahun 2014 hingga tahun 2017 adalah $11.39 \%$ [3].

Perbedaan nilai antara proyeksi RIP dan realisasi terkini belum memberikan nilai yang pasti untuk dipedomani dalam melaksanakan perencanaan dan pengembangan $\mathrm{CY}$ yang sesuai dengan arus B/M petikemas. Baik luas lahan yang tersedia maupun yang diprediksikan oleh RIP belum menunjukkan nilai yang optimal bagi pengguna dan operator kegiatan petikemas di Pelabuhan Parepare. Hal ini menarik perhatian peneliti untuk mengkaji lebih lanjut.

\section{Metode}

\subsection{Jenis dan Sumber Data Penelitian}

Data primer diperoleh dari hasil observasi lapangan saat kegiatan operasional petikemas di Pelabuhan Parepare, komunikasi dan berdialog langsung terhadap pengguna dan operator kegiatan operasional petikemas di CY Lontangnge. Selain itu dilakukan pula pemeriksaan CBR tanah dasar lapangan untuk menghitung besarnya kekuatan tanah dalam menopang beban petikemas.

Harga CBR adalah nilai yang menyatakan kualitas tanah dasar dibandingkan dengan bahan standar berupa batu pecah yang mempunyai nilai CBR sebesar $100 \%$ dalam memikul beban. Pelaksanaan pemeriksaan ini dilakukan dengan menggunakan alat Dynamic Cone Penetrometer (DCP) [4].Pemeriksaan CBR diperlukan sebagai bahan analisa perhitungan tinggi maksimum tumpukan petikemas yang digunakan sebagai dasar perhitungan kapasitas lapangan.

Data sekunder penulis peroleh melalui laporan rutin SIMOPEL dan ALPRO PT Pelabuhan Indonesia IV (Persero) Cabang Parepare, Manifest PT Mentari Sejati Perkasa, Nota Tagihan PT Pelindo IV (Persero) Cabang Parepare serta studi pustaka atau studi literatur yang berkaitan dengan kegiatan operasional petikemas. Data lainnya yang didapatkan oleh penulis yaitu berupa Dokumen Rencana Induk Pelabuhan Kota Parepare yang berisikan masterplan Pelabuhan Parepare hingga tahun 2025 meliputi Kompilasi Data, Analisis dan Prediksi, Rencana Pembangunan dan Pengembangan, Dokumen Peta-Peta dan Ringkasan Eksklusif.

\subsection{Teknik Pengumpulan dan Metode Analisis Data}

Observasi yang dilakukan dengan mengamati secara langsung fenomena atau karakteristik parameter yang ditinjau. Teknik Dokumentasi 
cara mengumpulkan data sekunder yang telah terdokumentasi, berupa arsip dan termasuk bukubuku tentang pendapat, teori dan dalil yang berhubungan dengan masalah penelitian.

Untuk analisis optimasi yaitu dengan melihat data yang telah terkumpul sebagai acuan faktor yang dapat menunjang pelabuhan peti kemas seperti:

- Realisasi muatan B/M petikemas;

- Realisasi arus kunjungan kapal petikemas;

- Luas lokasi untuk lapangan petikemas;

- Dwelling Time.

Model optimasi tingkat pemakaian lapangan penumpukan petikemas dapat dinyatakan melalui fungsi berikut.

$$
\begin{aligned}
& Y=f\left(X_{1}, X_{2}\right) \\
& X_{1}=f\left(Z_{1}, Z_{2}\right)
\end{aligned}
$$

Dimana $\mathrm{Y}$ adalah Tingkat pemakaian lapangan penumpukan petikemas optimum. $\mathrm{X}_{1}$ adalah Kapasitas lapangan penumpukan petikemas . $\mathrm{X}_{2}$ adalah muatan B/M. $Z_{1}$ adalah luas lapangan penumpukan. $\mathrm{Z}_{2}$ adalah dwelling time [5].

\section{Pembahasan}

Melalui hasil pemeriksaan tanah menggunakan alat DCP diperoleh nilai CBR sebesar $30.02 \%$. Dengan menggunakan struktur perkerasan sebagaimana ditunjukkan pada Gambar 2, maka diperoleh hasil bahwa tanah dasar Lapangan Penumpukan Petikemas Lontangnge mampu menahan beban sebesar 112.72 ton. Jika beban sebuah petikemas full adalah $24.000 \mathrm{~kg}$ maka kemampuan tanah dimaksud dapat menahan petikemas dengan tinggi tumpukan 4 (empat) tier. Hal ini tentu saja sangat mempengaruhi besarnya kapasitas lapangan.

Sampai dengan tahun 2017, luas aktual Lapangan Penumpukan Petikemas Lontangnge adalah $5.276 \mathrm{~m}^{2}$. Fasilitas lapangan dilengkapi dengan pagar pembatas/pengaman dan lampu penerangan. Alat yang beroperasi di lapangan adalah 2 (dua) buah forklift yaitu forklift 7 ton dan forklit 38 ton.

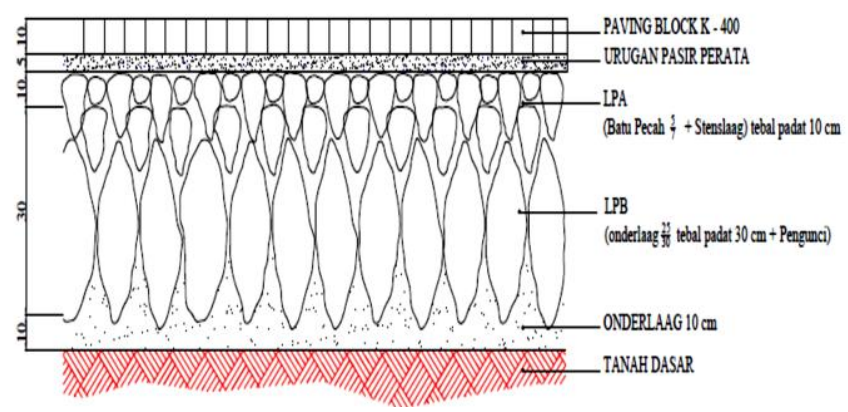

Gambar 2. Gambar desain struktur lapis perkerasan lapangan penumpukan petikemas lontangnge

Berdasarkan hasil perhitungan biaya user dan operator yang dilakukan dalam penelitian ini, maka tingkat pemanfaatan lapangan penumpukan optimum dapat ditentukan.

Adapun perhitungan biaya yang dilakukan dalam penelitian ini adalah sebagai berikut :

- Biaya Investasi Lapangan.

Lapangan Penumpukan Petikemas Lontangnge hingga saat ini telah dilakukan beberapa investasi dengan tujuan, pembangunan, penerangan, pengamanan asset dan pemeliharaan sebagaimana rekapitulasi nilai kontrak pekerjaan yang telah diprogramkan oleh PT Pelindo IV (Persero) Cabang Parepare.

- Biaya Menunggu Akibat Fasilitas Tidak Tersedia.

Biaya menunggu terdiri atas biaya kapal dan nilai barang pada petikemas. Untuk nilai barang petikemas terdiri atas komponen barang ekspor dan impor. Nilai barang ekspor untuk perhitungan tahun 2017, didekati melalui nilai beras yang diklaim pihak PT Mentari Sejati Perkasa saat terjadi banjir di Parepare. Barang impor Pelabuhan Parepare sebagain besar merupakan barang-barang produk PT Wings Surya Indonesia yang berasal dari kota Surabaya. Nilai barang impor untuk perhitungan ini didekati melalui jenisjenis produk dan komposisi prosentase masing-masing produk dalam suatu kapal, data ini diperoleh melalui Cargo Manifest Muatan PT Mentari Sejati Perkasa Cabang Parepare. 
Tabel 1. Rekapitulasi tingkat pertumbuhan $B / M$ lapangan petikemas lontangnge

\begin{tabular}{ccc}
\hline Interval Waktu & Tahun & $\begin{array}{c}\text { Proyeksi B/M } \\
\text { Petikemas } \\
\text { (Teus) }\end{array}$ \\
\hline Jangka Pendek & 2017 & 9,803 (Aktual) \\
\hline $\begin{array}{c}\text { Jangka } \\
\text { Menengah }\end{array}$ & 2022 & $54,581.87$ \\
\hline Jangka Panjang & 2027 & $72,866.89$ \\
\hline
\end{tabular}

Berikut adalah penentuan optimum lapangan untuk jangka pendek (5 tahun), jangka menengah (10 tahun) dan jangka panjang (15 tahun). Adapun tingkat pertumbukan B/M Petikemas Lapangan Penumpukan Petikemas Lontangnge Terhadap B/M Petikemas adalah sebagaimana Tabel 1.

\subsection{Jangka Pendek (Tahun 2017)}

Rekapitulasi pemanfaatan lapangan penumpukan optimum pada Jangka Pendek (Tahun 2017) digambarkan pada Tabel 2, dimana muatan $\mathrm{B} / \mathrm{M}$ petikemasnya merupakan angka aktual yang datanya diperoleh hingga 31 Desember 2017.

Pada Tabel 2 diperoleh nilai optimum berada pada luasan lapangan $4700 \mathrm{~m}^{2}$ dimana jumlah kedatangan petikemas adalah 9,803 teus/tahun, kapasitas pelayanan petikemas adalah 35,333 teus/tahun, besar YOR yaitu $27.74 \%$.

Biaya optimum user dan operator adalah $\mathrm{Rp}$. 27,479,774,886.03, nilai ini dianggap optimum dengan melihat total biaya yang terus meningkat sebanding dengan meningkatnya luas lapangan.

Tabel 2. Rekapitulasi tingkat pertumbuhan $\mathrm{B} / \mathrm{M}$ lapangan petikemas lontangnge pada jangka pendek

\begin{tabular}{ccccc}
\hline $\begin{array}{c}\text { Luas } \\
\text { Lap. } \\
\left(\mathbf{m}^{\mathbf{2}}\right)\end{array}$ & $\begin{array}{c}\text { Muatan } \\
\text { B/M } \\
\text { (Teus/ } \\
\text { Tahun) }\end{array}$ & $\begin{array}{c}\text { Kap. } \\
\text { (Teus/ } \\
\text { Tahun) }\end{array}$ & $\begin{array}{c}\text { YOR } \\
(\boldsymbol{\%})\end{array}$ & $\begin{array}{c}\text { Total Biaya Operator } \\
\text { dan User } \\
(\mathbf{R p})\end{array}$ \\
\hline 3000 & 9,803 & 22,553 & 43.47 & $28,236,012,808.02$ \\
\hline 3500 & 9,803 & 26,312 & 37.26 & $27,779,754,234.48$ \\
\hline 4000 & 9,803 & 30,071 & 32.60 & $27,562,892,385.94$ \\
\hline 4500 & 9,803 & 33,830 & 28.98 & $27,484,641,182.16$ \\
\hline 4600 & 9,803 & 34,581 & 28.35 & $27,480,629,163.08$ \\
\hline $\mathbf{4 7 0 0}$ & $\mathbf{9 , 8 0 3}$ & $\mathbf{3 5 , 3 3 3}$ & $\mathbf{2 7 . 7 4}$ & $\mathbf{2 7 , 4 7 9 , 7 7 4 , 8 8 6 . 0 3}$ \\
\hline 4800 & 9,803 & 36,085 & 27.17 & $27,481,833,117.65$ \\
\hline 5000 & 9,803 & 37,588 & 26.08 & $27,493,826,890.46$ \\
\hline
\end{tabular}

Namun pada luasan $4700 \mathrm{~m}^{2}$ total biaya yang terus meningkat kemudian turun dan kembali naik pada luasan $4800 \mathrm{~m}^{2}$. Untuk grafik Jangka Pendek (Tahun 2017) dapat digambarkan melalui Gambar 3 .

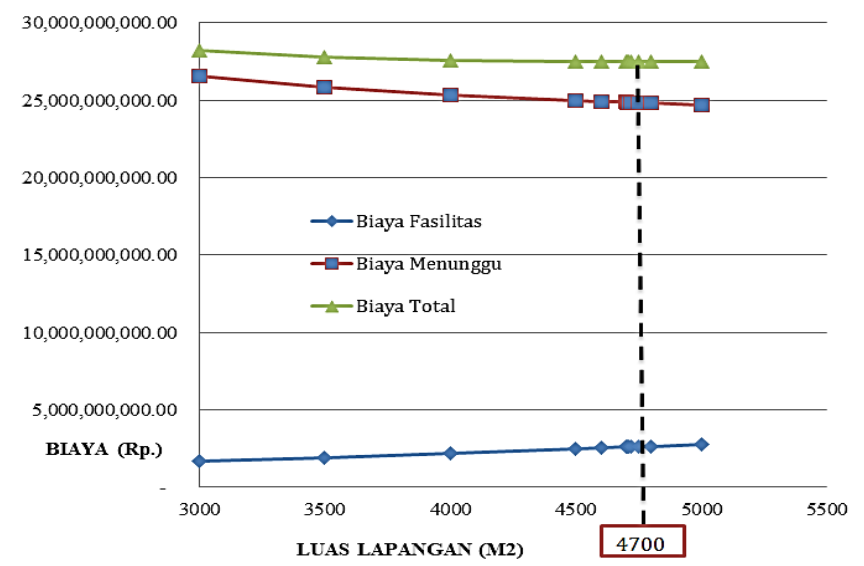

Gambar 3. Biaya optimum jangka pendek (Tahun 2017)

\subsection{Jangka Menengah (Tahun 2022)}

Rekapitulasi pemanfaatan lapangan penumpukan optimum pada Jangka Menangah (Tahun 2022) digambarkan pada Tabel 3 yaitu data pertumbuhan petikemasnya diambil dari hasil proyeksi pertumbuhan $\mathrm{B} / \mathrm{M}$ petikemas yang meningkat hingga 82.04\% terhadap tahun 2017.

Tabel 3. Rekapitulasi tingkat pertumbuhan B/M lapangan petikemas lontangnge pada jangka menengah

\begin{tabular}{ccccc}
\hline $\begin{array}{c}\text { Luas } \\
\text { Lap. } \\
\left(\mathbf{m}^{\mathbf{2}}\right)\end{array}$ & $\begin{array}{c}\text { Muatan } \\
\text { B/M } \\
\text { (Teus/ } \\
\text { Tahun) }\end{array}$ & $\begin{array}{c}\text { Kap. } \\
\text { (Teus/ } \\
\text { Tahun) }\end{array}$ & $\begin{array}{c}\text { YOR } \\
(\%)\end{array}$ & $\begin{array}{c}\text { Total Biaya } \\
\text { Operator dan User } \\
(\mathbf{R p})\end{array}$ \\
\hline 10,000 & 54,582 & 75,177 & 72.60 & $29,210,960,198.29$ \\
\hline 15,000 & 54,582 & 112,765 & 48.40 & $31,676,775,115.83$ \\
\hline 20,000 & 54,582 & 150,354 & 36.30 & $34,302,158,826.04$ \\
\hline 24,000 & 54,582 & 180,424 & 30.25 & $36,447,613,426.90$ \\
\hline 24,500 & 54,582 & 184,183 & 29.63 & $36,717,479,328.00$ \\
\hline 25,000 & 54,582 & 187,942 & 29.04 & $36,690,983,344.01$ \\
\hline 25,500 & 54,582 & 191,701 & 28.47 & $37,258,082,454.82$ \\
\hline 26,000 & 54,582 & 195,460 & 27.92 & $37,528,784,915.07$ \\
\hline 30,000 & 54,582 & 225,531 & 24.20 & $39,456,710,599.58$ \\
\hline
\end{tabular}

Pada Tabel 3 diketahui bahwa nilai optimum berada pada luasan lapangan $25,000 \mathrm{~m}^{2}$ dimana jumlah kedatangan petikemas adalah 54,582 teus/tahun, kapasitas pelayanan petikemas adalah 187,942 teus/tahun, besar YOR yaitu $29.04 \%$. Biaya optimum user dan operator adalah $\mathrm{Rp}$. 36,690,983,344.01, nilai ini dianggap optimum dengan melihat total biaya yang terus meningkat sebanding dengan meningkatnya luas lapangan. 
Namun pada luasan $25.000 \mathrm{~m}^{2}$ total biaya yang terus meningkat kemudian turun dan kembali naik pada luasan $25.500 \mathrm{~m}^{2}$.

\subsection{Jangka Panjang (Tahun 2027)}

Rekapitulasi pemanfaatan lapangan penumpukan optimum pada Jangka Menengah (Tahun 2022) digambarkan pada Tabel 4.

Tabel 4. Rekapitulasi tingkat pertumbuhan $\mathrm{B} / \mathrm{M}$ lapangan petikemas lontangnge pada jangka panjang

\begin{tabular}{ccccc}
\hline $\begin{array}{c}\text { Luas } \\
\text { Lap. } \\
\left(\mathbf{m}^{\mathbf{2}}\right)\end{array}$ & $\begin{array}{c}\text { Muatan } \\
\text { B/M } \\
\text { (Teus/ } \\
\text { Tahun) }\end{array}$ & $\begin{array}{c}\text { Kap. } \\
\text { Teus/ }\end{array}$ & $\begin{array}{c}\text { YOR } \\
\mathbf{( \% )}\end{array}$ & $\begin{array}{c}\text { Total Biaya Operator } \\
\text { dan User } \\
(\mathbf{R p})\end{array}$ \\
\hline 10,000 & 72,867 & 75,177 & 96.93 & $29,210,960,198.29$ \\
\hline 15,000 & 72,867 & 112,765 & 64.62 & $31,676,775,115.83$ \\
\hline 20,000 & 72,867 & 150,354 & 48.46 & $34,302,158,826.04$ \\
\hline 24,000 & 72,867 & 180,424 & 40.39 & $36,447,613,426.90$ \\
\hline 24,500 & 72,867 & 184,183 & 39.56 & $36,717,479,328.00$ \\
\hline 25,000 & 72,867 & 187,942 & 38.77 & $36,690,983,344.01$ \\
\hline 25,500 & 72,867 & 191,701 & 38.01 & $37,258,082,454.82$ \\
\hline 26,000 & 72,867 & 195,460 & 37.28 & $37,528,784,915.07$ \\
\hline 30,000 & 72,867 & 225,531 & 32.31 & $39,456,710,599.58$ \\
\hline
\end{tabular}

Untuk Jangka Menengah (Tahun 2022) muatan B/M petikemasnya diambil dari hasil proyeksi pertumbuhan $\mathrm{B} / \mathrm{M}$ petikemas yang meningkat hingga $86.55 \%$ terhadap tahun 2017 .

Pada Tabel 4 diketahui bahwa nilai optimum masih berada pada luasan lapangan 25,000 $\mathrm{m}^{2}$ dimana jumlah kedatangan petikemas adalah 72,867 teus/tahun, kapasitas pelayanan petikemas adalah 187,942 teus/tahun, besar YOR yaitu $38.77 \%$ serta biaya optimum user dan operator adalah Rp. 36,690,983,344.01.

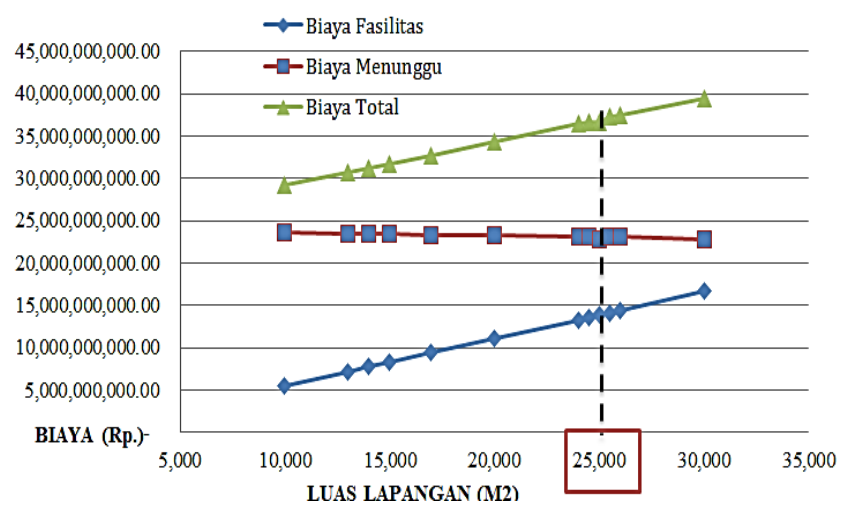

Gambar 4. Biaya optimum jangka menengah (Tahun 2022)
Untuk grafik Jangka Panjang (Tahun 2027) dan grafik Jangka Menengah (Tahun 2022) memiliki luas lapangan optimum yang sama sehingga dapat digambarkan melalui Gambar 4.

\section{Kesimpulan}

Jangka Pendek (tahun 2017) diperoleh nilai optimum berada pada luasan lapangan $4700 \mathrm{~m}^{2}$ dimana jumlah kedatangan petikemas adalah 9,803 teus/tahun, kapasitas pelayanan petikemas adalah 35,333 teus/tahun, besar YOR yaitu $27.74 \%$ serta biaya optimum user dan operator adalah Rp. 27,479,774,886.03.

Jangka Menengah (tahun 2022) diperoleh nilai optimum berada pada luasan lapangan $25,000 \mathrm{~m}^{2}$ dimana jumlah kedatangan petikemas adalah 54,582 teus/tahun, kapasitas pelayanan petikemas adalah 187,942 teus/tahun, besar YOR yaitu $29.04 \%$ serta biaya optimum user dan operator adalah Rp. 36,690,983,344.01.

Jangka Panjang (Tahun 2027) diperoleh nilai optimum masih berada pada luasan lapangan $25,000 \mathrm{~m}^{2}$ dimana jumlah kedatangan petikemas adalah 72,867 teus/tahun, kapasitas pelayanan petikemas adalah 187,942 teus/tahun, besar YOR yaitu $38.77 \%$ serta biaya optimum user dan operator adalah Rp. 36,690,983,344.01.

\section{Referensi}

[1] Draft RIP Parepare, 2015.

[2] Misliah, 2012, Optimasi Pemanfaatan Lapangan Penumpukan Petikemas di Pelabuhan Indonesia IV (Persero) Ditinjau Dari Kepentingan Operator dan Pengguna, Program Pascasarjana Universitas Hasanuddin.

[3] PT Pelabuhan Indonesia IV (Persero), 2017, Sistem Informasi Manajemen dan Operasional Pelabuhan (SIMOPEL). Parepare.

[4] ASTM D6951-03, Standard Test Method for Use of the Dynamic Cone Penetrometer in Shallow Pavement Applications, ASTM International, West Conshohocken, PA, 2003, www.astm.org.

[5] Makridakis, S., Wheelwright, S.C., McGee,V.E.,1983. Forcasting. John Wiley \& Sons,Inc, Hanover. 